\title{
Surgical removal of equine ovarian masses - is less more?
}

\author{
Ellen J. van der Zaag ${ }^{1}$ and Carmen J. W. Scheffer ${ }^{2}$ \\ 'Veterinary clinic "de Delta", Maasland, The Netherlands \\ 2 Equine clinic "De Watermolen", Haaksbergen, The Netherlands
}

\begin{abstract}
Summary: This paper describes a retrospective study of 34 mares which had been subjected to surgical elective ovariectomy using a standing laparotomy technique by two experienced veterinary surgeons at 13 different equine clinics in the Netherlands over a 9-year period (20102018). Of the 34 mares that underwent surgery, $74 \%$ (25/34) were Warmbloods. Fifty-nine percent (20/34) had a mass in the right ovary and $41 \%$ in the left ovary. The primary presenting signs were behavioural and fertility issues. The mean age of the horses was 10 years $(5-18$ years). The procedure was performed in stocks with continuous infusion sedation and analgesia. Prior to surgery the horses routinely received antibiotics and non-steroidal anti-inflammatory drugs (NSAID's). The surgical site was anaesthetized using an inverted L-block. The paracostal incision was performed in a "grid- or partial grid" fashion. The length of the incision varied from 15-30 cm depending on the size of the mass. The affected ovary was manoeuvred into the laparotomy wound and the ovarian pedicle was infiltrated with local anaesthetic solution. Shortly thereafter the pedicle was crushed with an emasculator and ligated with absorbable suture material. The ovarian mass was removed and the stump inspected for bleeding prior to wound closure in separate layers. The mares remained hospitalized for between 5 and 7 days. The mean diameter of the operated ovaries was $18.5 \mathrm{~cm}(10-25 \mathrm{~cm})$. Surgical pathology was not always carried out but almost all cases showed a typical granulosa (theca) cell tumour (GCT) appearance and subsequent pathology, in 3 cases, confirmed that diagnosis. All laparotomy wounds healed per primam with only minor postoperative complications (seroma) and no further complications were reported over the following 3 months; all horses returned to their normal activity. Ovariectomy via a standing flank laparotomy is a relative safe, basic, straightforward and economic surgical procedure for the removal of pathologically enlarged ovaries. The procedure requires only restraint, sedation and local anaesthesia with standard, non-specialized instruments. This approach can be considered as a viable and effective surgical option.
\end{abstract}

Keywords: horse, ovarian mass, granulosa(theca)cell tumour, laparotomy, surgery

Citation: van der Zaag E. J., Scheffer C. J. W. (2019) Surgical removal of equine ovarian masses - is less more? Pferdeheilkunde 35, 113-119; DOI 10.21836/PEM20190202

Correspondence: Ellen J. van der Zaag, Veterinary clinic "de Delta", Foppenpolder 1, 3155 EA Maasland, The Netherlands; info@dierenkliniekdedelta.nl

\section{Introduction}

Historically, surgical techniques for ovariectomy, including standing colpotomy or flank laparotomy and flank, ventral or paramedian approaches under general anaesthesia, have been described (Trotter and Embertson 1992). Over the past decade minimally invasive surgery has become more applicable in both human and veterinary medicine. Equine laparoscopy was first reported in 1970 (Hendrickson 2012) and is the standard approach to modern surgical ovariectomy in mares (Caron 2012, Hendrickson 2012, Philips 2012). Some of the older techniques are also used in combination with laparoscopy (de Bont et al. 2010, Caron 2012, Colbath et al. 2017, Cokelaere et al. 2005, Farstvedt and Hendrickson 2005, Goodin et al. 2011, Hendrikson 2012, Kummer et al. 2010, Lund et al. 2014, Röcken et al. 2011, Smith and Devine 2013, Tate at al. 2012, Vitte et al. 2014). The choice of surgical technique is usually based on the size of the enlarged ovary, the temperament of the mare, the surgeon's preference and the available surgical equipment (Goodin et al. 2011). The "old-fashioned" flank laparotomy in a standing horse is a basic, straight forward surgical procedure with relatively limited costs and is therefore a reasonable alternative to the laparoscopic option (Maurice 2005). This retrospective study describes the surgical procedure and outcome of standing flank ovariectomy approach in 34 mares carried out by two veterinarians in 13 equine clinics in the Netherlands, to determine whether this technique is a serious option to consider.

\section{Materials and methods}

Case records from a number of practices relating to cases subjected to standing ovariectomy by two veterinary surgeons between 2010 and 2018 in 13 different practices in the Netherlands were studied. Thirty-four mares fulfilled the inclusion criteria. The stated indications for surgery included behavioural problems (stallion-like behaviour, aggression), fertility issues (abnormal estrus cycle, impaired fertilization), hind limb lameness and recurrent or persistent abdominal pain. The tentative diagnosis of the ovarian mass was made by repeated rectal palpation (to establish which ovary was involved and the size and nature of the ovary) in combination with ultrasonography. Prior to surgery all cases had been subjected to routine clinical evaluation and in some cases routine hematologic profiles. Additionally, serum hormone assays (testosterone, oestrogen, inhibin and anti-müllerian hormone (AMH) were performed in 4 cases. The more specific diagnosis was generally made by the macroscopic appearance of the ovarian mass after removal. Histopathologic examination of ovarian tissue was performed in 3 cases only.

\section{Surgical technique}

Patients ware fasted for 24 hours prior to surgery, restrained in stocks and the flank was clipped and disinfected. A 12 gauge catheter (Intraflon ${ }^{\mathrm{TM}}$ ) was placed in the jugular vein under asep- 
tic conditions. Preoperative medication included penicillin-procaine $^{1}(15 \mathrm{mg} / \mathrm{kg} \mathrm{IM})$, gentamicin $1(6.6 \mathrm{mg} / \mathrm{kg} \mathrm{IV})$ and flunixin meglumine ${ }^{1}(1 \mathrm{mg} / \mathrm{kg} \mathrm{IV})$. The horses were pre-medicated with detomedine $^{l}(10 \mu \mathrm{g} / \mathrm{kg} \mathrm{IV})$ and butorphanol' $(0.02 \mathrm{mg} / \mathrm{kg} \mathrm{IV})$, followed by continuous rate infusion of detomedine and butorphanol in an average dose of $0.3 \mu \mathrm{g} / \mathrm{kg} / \mathrm{min}$ and $10-15 \mu \mathrm{g} /$ $\mathrm{kg} / \mathrm{min}$ respectively (Hubbell 2009). The flank was anaesthetized using an inverted L-block with approximately $60 \mathrm{ml}$ of procaine hydrochloride with adrenaline tartrate?

A paracostal incision was made through the skin and subcutis; the length of the incision was adapted to the estimated overall size of ovary $(15-30 \mathrm{~cm})$. The external and internal abdominal oblique muscle and transverse abdominal muscle were split in the direction of their fibres ("grid-technique"). In a few cases a "partial grid technique" was performed in which the external abdominal oblique muscle had to be partially dissected. The peritoneum was perforated bluntly to gain entry into the abdomen.

Where a large cyst was identified in the affected ovary this was punctured intra-abdominally prior to removal with a 12 gauge needle and the fluid drained via a silicone tube. The affected ovary was manoeuvred into the incision site and the pedicle of the ovary and parts of the mesosalpinx and mesovarium were locally infiltrated with $20 \mathrm{ml}$ of procaine hydrochloride solution with adrenaline?. The pedicle was then crushed with an emasculator and ligated with polyglycolic acid USP 5/USP 6 - Where a large mass was present the pedicle was divided and separately crushed and ligated consecutively. After the ovarian mass was removed the remaining stump was carefully checked for bleeding.

The abdominal muscle incision was closed in 3 layers separately with simple interrupted sutures using polyglactine 910 USP 2, the subcutis was closed in a continues pattern with polyglactin 910 USP 2-0 and the skin sutured intradermally also with polyglactin 910 USP 2-0 or with simple interrupted sutures using nylon USP 0 , to the preference of the surgeon.

\section{Post-operative management and follow up}

The horses were confined to a stable at the clinic for approximately 5-7 days. Gentamicin $(6.6 \mathrm{mg} / \mathrm{kg} \mathrm{IV)} \mathrm{and} \mathrm{benzyl} \mathrm{peni-}$ cillin-procaine ${ }^{1}(15 \mathrm{mg} / \mathrm{kg}$ IM) were administered routinely for three days. Meloxicam ${ }^{1}(0.6 \mathrm{mg} / \mathrm{kg})$ was administered for approximately one week post-surgery depending on the wound condition, the post-operative pain response and the overall condition of the horse. The wound and rectal temperature were daily checked by a veterinarian at the concerned clinic. If required, the skin sutures were removed 10 days post-operative at the owners premises. The owner was advised to restrict exercise with 2 weeks box rest followed by $2-4$ weeks box rest with hand walking and access to a small paddock. Increasing exercise back to preoperative levels was introduced over the following 6-8 weeks.

\section{Results}

Of the mares $(n=34)$ that had surgery $74 \%(n=25)$ were Warmblood and $15 \%(n=5)$ were Friesian. Additionally, 1 pony, 1 Quarter horse, 1 Friesian x Arabian horse and 1 Arabian horse were operated. The right ovary was affected in $59 \%(n=20)$ of the mares and $41 \%(n=14)$ involved the left ovary. No mare required a bilateral procedure. The mean age of the mares was (5 to 18 years); the age of 5 horses was unknown. The mean size of the ovaries removed was $18.5 \mathrm{~cm}$ $(10-25 \mathrm{~cm})$; the size of the ovary was not known in 8 cases. Unfortunately, this was not registered in the patient file.

Surgical pathology was only preformed in 3 cases for a variety of reasons with cost, being the most important and frequent reason. A definitive diagnosis regarding the ovaries was therefore not established in most cases; in 28 cases (82\%) a granulosa (theca) cell tumour (GCT) was suspected (Fig. 1) based on the characteristic gross pathology. In 2 cases a hematoma and in 1 case a teratoma was suspected based on the appearance of the ovary. In 6 mares the affected ovary was drained intra-abdominally prior to removal to facilitate the delivery of the ovary into the surgical site.

The size of the surgical incision depended on the size of the ovarian mass and varied from $15-30 \mathrm{~cm}$. The surgery time varied from 45-100 minutes. The most important factors affecting the surgical time were the size of the tumour and the consequent size of the wound and the extent of manipulation required to manoeuvre large ovaries into the wound. In a few cases the external abdominal oblique muscle had to be partially dissected to gain a better access to remove the ovary mass. In some cases the moment of exteriorization of the ovary mass gave some reaction. Only 2 horses developed a seroma at the surgical site; only one mare required the wound to be drained. In both of these cases the wounds healed without further problems. Wound infection or dehiscence of the wound did not occur in any of the cases (Table 1). Some horses had a slightly elevated rectal temperature $\left(<38.5^{\circ} \mathrm{C}\right)$ for 1 or 2 days. Most of the horses recovered their full performance following the procedure and some had multiple foals thereafter.

The costs, in the Netherlands, of the surgical procedure varied between $€ 1000-€ 1200$.

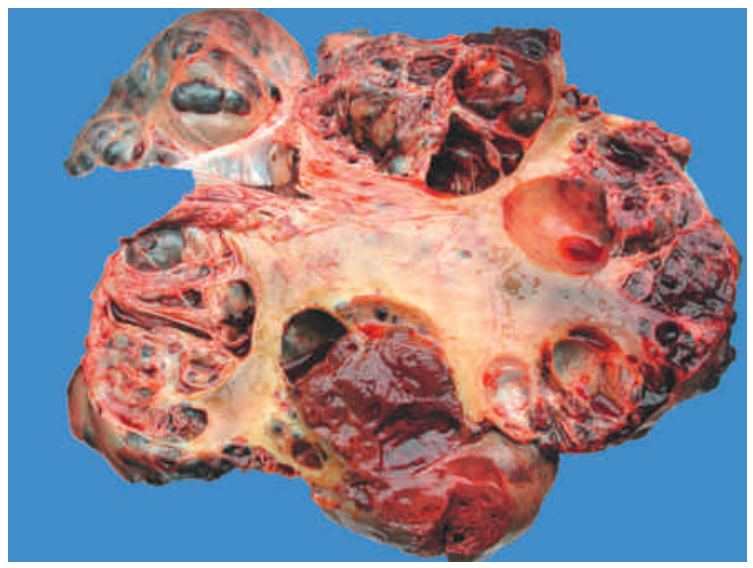

Fig. 1 Cut section of a granulosa cell tumor showing multiple, variably sized and fluid filled cystic structures that are lined by neoplastic granulosa cells. | Der Anschnitt eines Granulosazelltumors zeigt multiple, unterschiedlich große und flüssigkeitsgefüllte zystische Strukturen, welche mit neoplastischen Granulosazellen ausgekleidet sind. 


\section{Discussion}

Much is published concerning laparoscopic ovariectomy in mares (de Bont et al. 2010, Caron 2012, Colbath et al. 2017, Cokelaere et al. 2005, Farstvedt and Hendrickson 2005, Goodin et al. 2011, Hendrikson 2012, Kummer et al. 2010, Lund et al. 2014, Röcken et al. 2011, Smith and Devine 2013, Tate at al. 2012, Vitte et al. 2014). The minimal invasive laparoscopic method is considered by most of these authors to be first choice treatment for a small $(\leq 10 \mathrm{~cm})$ and medium $(>10-20 \mathrm{~cm}$ ) sized ovarian masses or when the mare has to be spayed due to behavioural issues. In recent literature, laparoscopy is, in most cases, mentioned in combination with laparotomy (de Bont et al. 2010, Cockelaere et al. 2005, Goodin et al. 2011, Röcken et al. 2011, Vanhaesebrouck et al. 2010). Laparoscopy in combination with a motorized morcellator technique (to reduce the size of the ovary) was advocated by Lund et al. (2014) and by Kummer et al. (2010). Smith and Devine (2013) and Tate et al. (2012) reported the combined use of laparoscopy and colpotomy. Röcken et al. (2011) described the treatment of 7 mares with relatively large ovarian tumours that initially involved laparoscopic dissection followed by a ventral midline laparotomy approach.

In our opinion there is limited benefit in laparoscopy if the incision has to be extended anyway or the horse has to undergo consequential general anaesthesia. Furthermore, when financial resources are limited for the procedure, the option of a simple standing laparotomy should be considered as a viable option. However a possible restriction in performing a flank laparotomy is that the costal arch and the limited size of the sub-lumbar fossa can limit the available space to manoeuvre the affected ovary. It can therefore be challenging to deliver a very enlarged ovary into the laparotomy "grid" site. As a result of this, the operation site sometimes has to be adapted to a "modified grid"- or "partial grid" approach. Additionally, the character of the horse, can be a significant factor on whether standing surgery can be performed safely. Overall it was remarkable how well tolerated this surgical technique was for the involved mares. Apparently sufficient sedation with effective analgesia and local infiltration at the surgical site results in a well-tolerated standing surgical flank procedure. However, extremely large tumours are generally best removed via a ventral midline or paramedial approach under general anaesthesia in dorsal recumbency (van der Zaag et al. 1996).

In the present cases only minor issues were noticed at the wound site. The majority of the lesions healed quickly and normally by primary healing. This is possibly due in part to the "grid" - or "partial grid" approach; this approach reduces the risk of haemorrhage and facilitates closure (Phillips 2012). Furthermore, the horses showed little signs of discomfort post-operatively for both smaller and larger wounds. The horses in this series were all otherwise healthy and did not undergo general anesthesia and this probably contributed to the very satisfactory rate and quality of healing.

According to Philips (2012) and Vanderhaesebrouck et al. (2010) ligation of the pedicle is often difficult because of the limited visibility within the abdomen. However, in our series we found that once the ovarian mass was manoeuvred into the wound, there was sufficient visibility to provide accurate local anaesthesia and to subsequently crush and ligate the pedicle, mesovarium and mesosalpinx in one or two steps.

A possible complication during laparoscopy while gaining entry into the abdomen is that the laparoscopic trocard can puncture an intestine or spleen (Palmer 2002). The advantage of a flank laparotomy approach is that the peritoneum is bluntly perforated and therefore these risks negligible.

Other complications after laparoscopy such as gas retention or pneumoperitoneum are recognised in human surgery (Sabezi Sarvestani and Zamiri 2014, Perugini and Callery 2001, Veekash et al. 2010). It is stated that gas retention in the peritoneal cavity plays an important role in inducing postoperative pain after laparoscopy (Sabezi Sarvestani and Zamiri 2014). In humans pneumoperitoneum can cause respiratory acidosis (presumably from absorption of the gas) but also can lead to hemodynamic alterations and even deep vein thrombosis (Perugini and Callery 2001). Complications are also encountered in small animal laparoscopic surgery; pneumoperitoneum and peritonitis of unknown origin after surgery are mentioned (Patel et al. 2014). Devick et al. (2018) recently evaluated residual pneumoperitoneum in mares associated with post-operative pain and concluded that active desufflation after surgery, to reduce the volume of gas, had no significant benefit. There are also occasional reports of fatal colitis following laparoscopy (personal communication M. Sloet). The cause of this is not clear, but it is assumed that factors such as stress and the concurrent use of antibiotics might play a role. None of the cases reported here showed any subsequent adverse complications.

The laparotomic approach in a standing horse to remove pathologically enlarged ovaries is a relatively straightforward surgical procedure. Only basic, preferably experienced, surgical skills are needed and minimal equipment is required. The ovary is optimally exposed when accessed from the flank site and operating time (depending on the size of the mass and experience of the surgeon) is relatively short. Simple sedation and local anaesthesia should be sufficient in most cases and therefore the costs are significantly less than laparoscopic or ventral midline laparotomy. Furthermore, incisional problems seem to be relatively rare and post-operative complications are also unusual. Nevertheless, the veterinary surgeon (and owner) should be aware that all abdominal surgery carry risks and therefore, overall, should not be taken lightly.

In conclusion, in our case series the laparotomic approach to ovariectomy appeared to be a suitable, cost-effective and relative safe procedure carrying an overall good prognosis.

\section{Conflict of interest}

There are no declarations of interest.

\section{Statement of informed consent}

The animal owners were informed that data concerning their horse were part of a scientific publication. 
Table 1 Patient data of 34 mares with pathological ovarian enlargement. | Patientendaten von 34 Stuten mit pathologischer Vergrößerung der Ovarien

\begin{tabular}{|c|c|c|c|c|c|c|c|c|c|c|}
\hline & Date & Breed & Age & $\begin{array}{c}\text { Main } \\
\text { problem }\end{array}$ & Tools & Site & $\begin{array}{c}\text { Susp } \\
\text { diagnosis }\end{array}$ & Size & Remarks & Follow up \\
\hline 1 & 08-09-2010 & Friesian & 9 & fertility & $R E$, US & R & Hematoma & $?$ & & no remarks \\
\hline 2 & $25-11-2010$ & Warmblood & 10 & fertility & RE, US & R & GCT & $20 \mathrm{~cm}$ & & no remarks \\
\hline 3 & $13-05-2011$ & Friesian & 7 & fertility & $R E, U S$ & L & GCT & $15 \mathrm{~cm}$ & & $\begin{array}{l}\text { same season pregn, } \\
5 \text { foals after surg. }\end{array}$ \\
\hline 4 & 03-02-2012 & Warmblood & $?$ & $?$ & & L & GCT+cyst & $?$ & & no remarks \\
\hline 5 & 22-08-2012 & Warmblood & 13 & fertility & $R E, U S$ & L & GCT+cyst & $25 \mathrm{~cm}$ & $\begin{array}{l}\text { pregnant while } \\
\text { operated }\end{array}$ & $\begin{array}{l}\text { normal birth, } \\
\text { breeding }\end{array}$ \\
\hline 6 & $18-06-2013$ & Warmblood & 8 & behaviour & RE, US & $R$ & $\begin{array}{l}\text { Hematoma } \\
+ \text { cyst }\end{array}$ & $25 \mathrm{~cm}$ & punction & in training \\
\hline 7 & $10-09-2013$ & Warmblood & 7 & behaviour & $R E, U S$ & $R$ & GCT & $25 \mathrm{~cm}$ & & in training \\
\hline 8 & $02-06-2014$ & Arabofriesian & & $?$ & RE, US & L & Teratoma & $?$ & & \\
\hline 9 & $10-06-2014$ & Warmblood & 10 & $\begin{array}{l}\text { behaviourt } \\
\text { locomotion }\end{array}$ & RE, US & L & GCT & $25 \mathrm{~cm}$ & & training + breeding \\
\hline 10 & $02-09-2014$ & Friesian & 10 & fertility & RE, US, hist & $R$ & GCT & $25 \mathrm{~cm}$ & & no remarks \\
\hline 11 & $02-12-2014$ & Warmblood & 10 & behaviour & RE, US & $\mathrm{R}$ & GCT+cyst & $15 \mathrm{~cm}$ & & in training \\
\hline 12 & 30-04-2015 & Warmblood & $?$ & $?$ & RE, US & R & GCT & $?$ & & no remarks \\
\hline 13 & 08-05-2015 & Warmblood & 17 & behaviour & $R E, U S$ & $\mathrm{R}$ & GCT & $25 \mathrm{~cm}$ & & no remarks \\
\hline 14 & $12-05-2015$ & Warmblood & $?$ & fertility & RE, US & $R$ & GCT & $10 \mathrm{~cm}$ & & breeding \\
\hline 15 & 01-07-2015 & Warmblood & 11 & fertility & $R E, U S$ & $R$ & GCT & $20 \mathrm{~cm}$ & & no remarks \\
\hline 16 & $02-05-2016$ & Warmblood & 17 & fertility & RE, US & R & GCT & $15 \mathrm{~cm}$ & & no remarks \\
\hline 17 & $26-05-2016$ & Warmblood & 14 & fertility & $R E, U S$ & L & GCT+cyst & $20 \mathrm{~cm}$ & $\begin{array}{c}\text { punction cyst/ } \\
\text { PO seroma punction }\end{array}$ & no remarks \\
\hline 18 & 13-07-2016 & Warmblood & 18 & colic & RE, US & L & Cyst & $?$ & $\begin{array}{c}\text { punction } \\
\text { Adhes colon desc }\end{array}$ & $\begin{array}{l}\text { in training - low } \\
\text { body score }\end{array}$ \\
\hline 19 & $10-10-2016$ & Quarter horse & $?$ & $?$ & $R E, U S$ & $R$ & GCT & $?$ & & no remarks \\
\hline 20 & $28-10-2016$ & Warmblood & 11 & fertility & $R E, U S$ & L & GCT + cysts & $20 \mathrm{~cm}$ & punction & no remarks \\
\hline 21 & 14-03-2017 & Warmblood & 18 & fertility & RE, US & $R$ & GCT & $?$ & & no remarks \\
\hline 22 & 08-05-2017 & Arabian & 6 & $?$ & RE, US & $R$ & GCT & $15 \mathrm{~cm}$ & & no remarks \\
\hline 23 & 09-05-2017 & Warmblood & 15 & behaviour & $R E, U S$ & L & GCT & $?$ & & training + breeding \\
\hline 24 & $22-05-2017$ & Warmblood & 5 & $?$ & RE, US & $R$ & GCT & $25 \mathrm{~cm}$ & & no remarks \\
\hline 25 & $31-05-2017$ & Welsh Pony & 8 & behaviour & RE, US, test & $R$ & GCT & $10 \mathrm{~cm}$ & & no remarks \\
\hline 26 & $11-07-2017$ & Warmblood & 12 & behaviour & RE, US, AMH & L & GCT+cyst & $15 \mathrm{~cm}$ & & in training \\
\hline 27 & 19-07-2017 & Warmblood & 10 & fertility & $R E, U S$ & L & GCT & $10 \mathrm{~cm}$ & & breeding \\
\hline 28 & 03-10-2017 & Warmblood & 12 & behaviour & RE, US & $\mathrm{R}$ & GCT+ cysts & $15 \mathrm{~cm}$ & punction & no remarks \\
\hline 29 & 09-10-2017 & Warmblood & $?$ & $?$ & $R E, U S$ & L & GCT & $?$ & & no remarks \\
\hline 30 & $31-01-2018$ & Friesian & 7 & $\begin{array}{l}\text { behaviour+ } \\
\text { locomotion }\end{array}$ & $\begin{array}{l}\text { RE, US, test } \\
\text { hist }\end{array}$ & $R$ & GCT & $12 \mathrm{~cm}$ & & in training \\
\hline 31 & $13-04-2018$ & Warmblood & 9 & fertility & $R E, U S$ & L & GCT & $15 \mathrm{~cm}$ & minimal seroma & no remarks \\
\hline 32 & $30-04-2018$ & Friesian & 10 & fertility & $\begin{array}{l}\text { RE, US, test } \\
\text { hist }\end{array}$ & $R$ & GCT & $15 \mathrm{~cm}$ & & in training \\
\hline 33 & $24-05-2018$ & Warmblood & 6 & behaviour & $R E, U S$ & L & GCT + cysts & $20 \mathrm{~cm}$ & punction & no remarks \\
\hline 34 & $25-07-2018$ & Warmblood & 10 & behaviour & RE, US & $R$ & GCT & $25 \mathrm{~cm}$ & & no remarks \\
\hline
\end{tabular}

$\mathrm{AMH}=$ anti-müllerian hormone, $\mathrm{GCT}=$ Granulosa Cell Tumour, hist $=$ histology, $?=$ unknown, test $=$ testosterone, $\mathrm{US}=$ ultrasound, $\mathrm{RE}=$ rectal examination $\mathrm{AMH}=$ Anti-Müller-Hormon, GCT = Granulosazelltumor, hist= Histologie, ? = unbekannt, test=Testosteron, US = Ultraschalluntersuchung, RE= rektale Untersuchung 


\section{Acknowledgements}

The authors wish to thank the clinics for providing and collecting the patient data and prof. Derek Knottenbelt and prof. Marianne Sloet.

\section{Manufacturer's address}

'Due to the fact that the surgeries took place at 13 different clinics, the manufacturers of the pharmaceuticals and suture material used differed.

\section{References}

Caron J. P. (2012) Equine laparoscopy: equipment and basic principles. Comp. Contin. Educ. Vet. 34, E1-7

Cokelaere S. M., Martens A. M. J. G., Wiemer P. (2005) Laparoscopic ovariectomy in mares using a polyamide tie-rap. Vet. Surg. 34, 651656

Colbath A. C., Hackett E. S., Lesser C. S., Hendrickson D. A. (2017) Left paralumbar laparoscopic bilateral ovariectomy in mares. Vet. Surg. 46, 574-579

De Bont M. P., Wilderians H., Simon O. (2010). Standing laparoscopic ovariectomy technique with intraabdominal dissection for removal of large pathologic ovaries in mares. Vet. Surg. 39, 737-74

Devick I. F., Leise B. S., Rao S., Hendrickson D. A. (2018) Evaluation of post-operative pain after active desufflation at completion of laparoscopy in mares undergoing ovariectomy. Can. Vet. J. 59, 261-266

Farstvedt E. G., Hendrickson D. A. (2005) Intraoperative pain responses following intraovarian versus mesovarian injection of lidocaine in mares undergoing laparoscopic ovariectomy. J. Am. Vet. Med. Assoc. 15, 593-596

Goodin J. T., Rodgerson D. H., Gomez J. H. (2011). Standing hand-assisted laparoscopic ovariectomy in 65 mares. Vet. Surg. 40, 90-92

Hendrickson D. A. (2012) A review of equine laparoscopy. Vet. Sci. Oct 24, DOI 10.5402/2012/492650

Hubbell J. A. E. (2009) Practical standing chemical restraint of the horse. Proceedings of the 55 st Annual Convention of American Association of Equine Practitioners, Las Vegas, NV, USA. Dec 5-9, 2009

Kummer M., Theiss F., Jackson M., Fürst A. (2010) Evaluation of a motorized morcellator for laparoscopic removal of granulosa-theca cell tumors in standing mares. Vet. Surg. 39, 649-653
Lund C. M., Ragle C. A., Lutter J. D., Farnsworth K. D. (2014) Use of a motorized morcellator for elective bilateral laparoscopic ovariectomy in standing equids: 30 cases (2007-2013). J. Am. Vet. Med. Assoc. 10, 1191-1197

Maurice K. T. (2005) Diagnosis and surgical removal of a granulosa-theca cell tumor in a mare. Can. Vet. J. 46, 644-646

Palmer S. E. (2002) Laparoscopic ovariectomy in the standing horse. In: Equine Diagnostic Surgical Laparoscopy, W.B. Saunders Company, Philadelphia, 189-196

Patel A. M., Parikh P. V., Patil D. B. (2014) Laparoscopy in veterinary practice. Vet. Res. Int. 2, 1-7

Perugini R. A., Callery M. P. (2001) Complications of laparoscopic surgery. In: Surgical treatment: Evidence-based and problem oriented. Holzheimer R. G, Mannick J. A (eds.), Munich, Zuckschwerdt

Phillips T. (2012) How to perform a successful ovariectomy. Proceedings of the 51 st British Equine Veterinary Association Congress, Birmingham, UK. Sep 12-15, 2012

Röcken M., Mosel G., Seyrek-Intas K., Seyrek-Intas D., Litzke F., Verver J., Rijkenhuizen A. B. M. (2011) Unilateral and bilateral laparoscopic ovariectomy in 157 mares: a retrospective multicenter study. Vet. Surg. 40, 1009-1014

Sabzi Sarvestani A., Zamiri M. (2014) Residual pneumoperitoneum volume and postlaparoscopic cholecystectomy pain. Anesth. Pain Med. 4, e 17366

Smith S. E., Devine D. V. (2013) Hand-assisted laparoscopic ovariectomy and colpotomy in standing mares. Vet. Surg. 42, 586-590

Tate L. P., Fogle C. A., Bailey C. S., Tate K. B., Davis J. W. (2012) Laparoscopic-assisted colpotomy for ovariectomy in the mare. Vet. Surg. $41,625-628$

Trotter G. W., Embertson R. M. (1992) Surgical disease of the cranial reproductive tract. In: Equine Surgery, Auer J. A. (ed.), W. B. Saunders Company, Philadelphia, 750-761

Van der Zaag E. J., Rijkenhuizen A. B., Kalsbeek H. C., Peperkamp N. H. (1996). A mare with colic caused by an ovarian tumour. Vet. Q. 18, 60-62

Vanhaesebrouck E., Govaere J., Smits K., Durie I., Vercauteren G., Martens A., Schauvliege S., Ducatelle R., Hoogewiis M., De Schauwer C., de Kruif A. (2010) Ovarian teratoma in the mare: a review and two cases. Vlaams Diergeneesk. Tijdschr. 79, 32-4 1

Veekash G., Wei L. X., Su M. (2010) Carbon dioxide pneumoperitoneum, physiologic changes and anesthetic concerns. Ambul. Surg. 16, 41-46

Vitte A., Rossignol F., Mespoulhes-Rivière C., Lechartier A., Röecken M. (2014). Two-step surgery combining standing laparoscopy with recumbent ventral median celiotomy for removal of enlarged pathologic ovaries in 20 mares. Vet. Surg. 43, 663-667 